\title{
PENGARUH HIPNOTERAPI TERHADAP IBU PRALANSIA DENGAN HIPERTENSI DI KELURAHAN SETIAMULYA KOTA TASIKMALAYA
}

\author{
Dita Eka Mardiani ${ }^{1}$, Debby Inda Rabbi², Nunung Mulyani \\ 1,2,3 Poltekkes Kemenkes Tasikmalaya
}

\begin{abstract}
The high rate of hypertension in pre-elderly mothers is because there are still many patients who have not been able to restrain or control hypertension blood pressure and require a combination intervention of pharmacological drugs andnon-pharmacological medication. The purpose of this research is to find out the influence of hypnotherapy on blood pressure in pre-elderly mothers with hypertension. Methodology. The research is aquasi-experimental research with One-group pre-post-test design. The population includes 62 pre-elderly mothers with hypertension, and 30 samples were chosen using Purposive Sampling. The variables are hypnotherapy and blood pressure. This research uses blood pressure meter and stethoscope as instruments. Wilcoxon test is used to analyze the data. Discussion of this study is before hypnotherapy was conducted, most of the systole is 140 and the diastole is 90 . Where as, after the hypnotherapy is done, almost all respondents have undergone changes, with most of the systole is 120 and the diastole is 80 . Wilcoxon test results significance ( $p$ value) $0.000<0.05$. Conclusion of this research is that there is an influence of hypnotherapy on blood pressure in pre-elderly mothers with hypertension in Kelurahan Setiamulya under the work territory of Puskesmas Tamansari Kota Tasikmalaya. When the respondents are given hypnotherapy, endorphin is released which makes the body feels comfort and happy, life quality can increase and blood pressure can be controlled.
\end{abstract}

Keywords : hypertension; hypnotherapy; pre-elderly 


\section{PENDAHULUAN}

Hipertensi menjadi salah satu sumbangsih terbanyak untuk angka kematian disebabkan gejala khas dari penyakit ini tidak dirasakan oleh penderitanya. Hipertensi dapat menyerang semua orang dari segala usia terutama pada lanjut usia (lansia). Pada lanjut usia, hipertensi merupakan penyakit utama. Hipertensi juga diartikan tekanan darah persisten dimana tekanan sistoliknya diatas $140 \mathrm{mmHg}$ dan tekanan diastolik diatas $90 \mathrm{mmHg}$. (Dinas Kesehatan Kota Tasikmalaya, 2018)

\section{Data World Health Organization} (WHO) tahun 2015 menunjukan sekitar 972 juta orang di dunia menderita hipertensi. Kematian akibat penyakit kardiovaskuler di Indonesia termasuk hipertensi, sebanyak 2.577 kasus. Pada tahun 2016 di Jawa Barat ditemukan 790.382 orang kasus hipertensi. Di Kota Tasikmalaya pada tahun 2018, penderita hipertensi primer pada usia 45-59 tahun (pra-lansia) khususnya jenis kelamin perempuan sebanyak 7.137 orang. Dari 21 puskesmas yang ada di kota Tasikmalaya, jumlah penderita hipertensi usia pra-lansia tertinggi di wilayah kerja puskesmas Tamansari, dimana sebanyak 752 orang berjenis kelamin perempuan menderita hipertensi dan khususnya di kelurahan Setiawargi paling banyak penderita hipertensi dengan jumlah 62 orang. ( Closkey, JC, \& Bulecheck, 2009)
Tingginya angka kejadian hipertensi pada lansia serta begitu banyaknya komplikasi yang mengakibatkan hipertensi karena hipertensi bukan merupakan Faktor penyebab tunggal. Maka, perlu adanya pengobatan dengan obat yang divariasikan dengan pengobatan non farmakologis salah satunya yaitu hipnoterapi. (Closkey, JC, \& Bulecheck, 2009)

Hipnoterapi ini menggunakan kekuatan sugesti yang akan langsung merelaksasikan kondisi klien, sehingga dapat menjadi lebih nyaman dalam waktu yang cukup singkat. Dampak yang diharapakan yaitu hipnoterapi dapat membantu merilekskan serta menurunkan tekanan darah, memulihkan kondisi fisik dan meringankan respon psikoemosional klien. (Sutrisno, Rahmawati, dan Haryanto, 2016)

\section{METODE}

Metode penelitian ini yaitu penelitian kuantitatif menggunakan desain penelitian quasi eksperiment designs dan rancangan one-group pra-post test design. Penelitian ini dilakukan pada bulan Maret 2020 di Kelurahan Setiamulya, Kota Tasikmalaya. Populasi meliputi ibu pralansia dengan hipertensi berjumlah 62 responden, diambil menggunakan Purposive Sampling. Pengambilan sampel pada penelitian ini dengan menetapkan kriteria inklusi agar dapat mewakili populasi yaitu lbu yang 
memiliki Hipertensi stage 1 (Tekanan Sistolik 140 - 159/Tekanan Diastolik 90 - 99) ; tidak mengalami komplikasi lain (strok, gagal ginjal kronik, gagal jantung), memahami komunikasi verbal; tidak sedang mengkonsumsi obat anti hipertensi. Sampel yang memenuhi kriteria penelitian adalah 30 orang.

Instrumen penelitian menggunakan form hipnoterapi, tensimeter dan stetoscope. Pada ibu pralansia dilakukan pengukuran tekanan darah sebanyak $2 x$, pemeriksaan pertama dan yang kedua dilakukan setelah 5 menit dari pemeriksaan pertama. Intervensi diberikan sebanyak 1 sesi (1x dalam 1 hari). Analisa data menggunakan uji wilcoxon.

\section{HASIL}

Berdasarkan penelitian yang telah dilakukan didapatkan hasil sebagai berikut : Tabel 1. Nilai rata-rata Pengukuran Tekanan Darah sebelum dan sesudah dilakukan Hipnoterapi pada lbu Pra Lansia dengan Hipertensi di wilayah kerja Puskesmas Tamansari Kota Tasikmalaya Tahun 2020

\begin{tabular}{lcc}
\hline \multirow{2}{*}{$\begin{array}{c}\text { Tekanan } \\
\text { Darah } \\
(\mathrm{mmHg})\end{array}$} & \multicolumn{2}{c}{ Rata-rata } \\
\cline { 2 - 3 } & Pretest & Posttest \\
\hline Sistole & 145.00 & 126.03 \\
\hline Diastole & 91.17 & 81.03 \\
\hline
\end{tabular}

Berdasarkan tabel 1, didapatkan bahwa hasil pemeriksaan tekanan darah sebelum dilakukan intervensi hipnoterapi didapatkan nilai rata-rata sistole 145.00 $\mathrm{mmHg}$ dan diastole $91.17 \mathrm{mmHg}$, setelah dilakukan hipnoterapi hampir semua responden mengalami perubahan dari nilai rata-rata sistole $126.03 \mathrm{mmHg}$ dan diastole $81.03 \mathrm{mmHg}$.

Hasil uji normalitas data dengan menggunkan Shapiro-Wilk pada penelitian ini didapatkan data berdistribusi tidak normal yaitu dengan hasil signifikansi pre-post sistole 0.005 dan hasil signifikan pre post diastole 0.004 , sehingga analisis selanjutnya menggunakan uji Wilcoxon.

Tabel 2. Analisis Tekanan Darah pada Ibu Pra Lansia dengan Hipertensi Sebelum dan Sesudah dilakukan Hipnoterapi

Tekanan Darah Mean $\quad$ SD $\quad$ Z $\quad p$ value

\begin{tabular}{|c|c|c|}
\hline \multicolumn{3}{|l|}{ Sistole } \\
\hline Sebelum & 145.005 .571 & -4.8360 .000 \\
\hline Sesudah & 126.035 .408 & \\
\hline \multicolumn{3}{|l|}{$\overline{\text { Diastole }}$} \\
\hline Sebelum & 91.17 & -4.9940 .000 \\
\hline Sesudah & 81.03 & \\
\hline
\end{tabular}

Berdasarkan tabel 2, hasil analisis bivariat menggunakan uji Wilcoxon didapatkan untuk pre-post sistole nilai $Z$ sebesar -4,836 untuk pre- post sistole nilai $p \quad 0,000(a<0,05\}$ dan untuk pre-post diastole nilai 2 sebesar $-4,994$ untuk pre-post diastole nilai $p 0,000$ (a $<0,05\}$. yang menunjukan terdapat pengaruh sebelum dan sesudah dilakukan hipnoterapi pada tekanan darah ibu pra lansia dengan hipertensi. Nilai probabilitas $p$ value $<0,05$ 
berarti Ha diterima dan Ha ditolak. Hal ini menujukkan terjadi penurunan tekanan darah ibu pra lansia dengan hipertensi setelah melakukan hipnoterapi.

\section{PEMBAHASAN}

Berdasarkan hasil penelitian dari 30 responden, tekanan darah sebelum diberikan hipnoterapi adalah nilai rata-rata sistole yaitu $145.00 \mathrm{mmHg}$ dan nilai rata-rata diastole yaitu $91.17 \mathrm{mmHg}$ yang termasuk ke dalam klasifikasi hipertensi stage 1.

Konsep teori yang sesuai dengan hasil yang didapatkan tersebut adalah mengenai hipertensi. Hipertensi adalah peningkatan tekanan darah pada sistolik lebih dari 140 dan tekanan darah diastolik lebih dari $90 \mathrm{mmHg}$ pada dua kali pengukuran dengan jeda waktu lima menit dalam keaadaan cukup istirahat/tenang. Hipertensi di klasifikasikan menjadi pre- hipertensi atau tekanan sistolik 120-139 dan diastolik 80-89 mmHg, hipertensi stage 1 atau tekanan sistolik 140159 dan diastolik 90-99 $\mathrm{mmHg}$, dan hipertensi stage 2 atau tekanan sistolik $>160$ dan diastolik $>100 \mathrm{mmHg}$. (Nurddin, Irfan, 2019)

Ada bebrapa faktor yang dapat mempengaruhi perubahan tekanan darah salah satunya yaitu usia. Insiden hipertensi meningkat sesuai dengan peningkatan usia. Usia berpengaruh pada baroreseptor yang berperan dalam regulasi tekanan darah dan berpengaruh pada elastisitas pada pembuluh darah arteri. Arteri menjadi kurang elastis ketika tekanan melalui dinding aneri meningkat. Hal ini sering terlihat peningkatan secara bertahap tekanan sistolik sesuai dengan peningkatan usia. Faktor lainya yang dapat menyebabkan hipertensi yaitu faktor genetik, jenis kelamin, ras, diabetes mellitus, tingkat stress, obesitas, merokok, konsumsi tinggi garam, alkohol, dan konsumsi kafein yang berlebih. (Nurddin, Irfan. 2019)

Berdasarkan hasil dari penelitian menunjukan bahwa dari 30 responden ratarata tekanan darah sesudah diberikan hipnoterapi terdapat nilai rata-rata sistole yaitu $126.03 \mathrm{mmHg}$ dan nilai rata-rata diastole yaitu $81.03 \mathrm{mmHg}$.

Dari hasil penelitian tersebut yaitu penerapan hipnoterapi dapat berpengaruh yang sangat baik terhadap penurunan tekanan darah pada penderita hipertensi. Hipnoterapi merupakan bagian cabang ilmu psikologi yang mempelajari pemanTaatan sugesti untuk mengatasi masalah psikologis yang meliputi pikiran, perasaan dan perilaku. Hipnoterapi merupakan suatu aplikasi modern dalam teknik kuno yang mengaplikasikan trance hypnosis. Hypnosis merupakan salah satu komunikasi yang Tujuan untuk memengaruhi seseorang sehingga mengubah tingkat kesadarannya, kondisi sadar yang terjadi secara alami seseorang mampu menghayati pikiran dan 
sugesti tertentu untuk mencapai perubahan psikologis, fisik maupun spiritual yang diinginkan dengan cara menurunkan gelombang otak dari beta menjadi alpha, theta dan delta. (Laksana, 2016)

Teori tersebut sesuai dengan hasil penelitian dari Irma bahwa, hipnoterapi dilakukan dengan membimbing klien untuk memasuki kondisi trance (relaksasi pikiran) dan setelah kon disi rileks tercapai maka pikiran bawah sadar akan terbuka sehingga seseorang dapat menerima sugesti positif dengan mudah. (Irma dan Vera, 2019)

Hasil penelitian tentang pengaruh hipnoterpi terhadap tekanan darah penderita hipertensi menunjukan bahwa terdapat pengaruh hipnoterapi terhadap tekanan darah pada penderita hipertensi dengan nilai signifikansi ( $p$ value) $0,000<0,05$. Sebelum diberikan hipnoterapi dengan nilai terbanyak sistole 140 dan diastole 90. Sesudah diberikan hipnoterapi terhadap tekanan darah penderita hipertensi terdapat perubahan penurunan tekanan darah dengan nilai terbanyak sistole 120 dan diastole 80. Dalam penelitian ini salah satu faktor yang mempengaruhi perubahan penurunan hipertensi adalah terapi nonfarmakologi yaitu hipnoterapi, oleh sebab itu dengan terapi nonfarmakologi hipnoterapi responden mengalami perubahan tekanan darah pada penderita hipertensi.

Pada saat dilakukan hipnoterapi responden dibimbing untuk melakukan relaksasi. Respon relaksasi ini terjadi melalui penurunan bermakna dari kebutuhan zat oksigen oleh tubuh, selanjutnya otot-otot tubuh yang relaks menimbulkan perasaan tenang dan nyaman. Aliran darah akan lancar, neurotransmiter penenang akan dilepaskan dan sistem saraf akan bekerja secara baik, dan setelah kondisi relaksasi tercapai maka secara alamiah gerbang pikiran bawah sadar akan terbuka, Sehingga akan lebih mudah menerima sugesti penyembuhan yang diberikan. (Sutrisno, Rahmawati, dan Haryanto, 2016)

Teori tersebut diperkuat dengan penelitian yang dilakukan oleh Rifki yang menyatakan bahwa, penurunan tekanan darah ini terjadi karena secara fisiologis saat seseorang masuk relaksasi hipnosis, gelombang pikirannya masuk ke gelombang alfa frekuensinya 7-14 hertz atau lebih dalam lagi ke gelombang theta frekuensinya 4-7 hertz. Ketika pikiran seseorang masuk ke gelombang ini, manusia menghasilkan zat endorphin alami yang menghasilkan sensasi nyaman, dan tubuh menjadi rileks. Dan dalam hypnosis state ini, sistem metabolisme tubuh menjadi jauh lebih baik dan tubuh bebas dari ketegangan. Sehingga terjadi respon saraf otonom penurunan tekanan darah, nadi, dan pernafasan. Pendapat diatas diperkuat dengan penelitian dari Holdevici dan Craciun (2012) tentang The Role of Ericksonian Hypnosis in 
Reducing Essential and Secondary Hypertension, hipnoterapi dengan menggunakan teknik Hypnosis terbukti bisa meningkatkan kualitas hidup dengan menurunkan tekanan darah pada pasien hipertensi. Hal ini disebabkan terjadinya pelepasan endorphin yang membuat tubuh menjadi nyaman dan bahagia, kualitas hidup menjadi meningkat dan tekanan darah bisa terkontrol. (Rifki, Arif dan Leo Yosdimyati, 2018)

\section{KESIMPULAN}

Terjadi penurunan pada hasil pemeriksaan darah sistolik sejak sebelum dilakukan dengan setelah tindakan intervesnsi adalah dari $145.00 \mathrm{mmHg}$ turun $126.03 \mathrm{mmHg}$. Penurunan hasil pemeriksaan juga terjadi pada diastolic dimana sebelum intervensi $91.17 \mathrm{mmHg}$ dan sesudah dilakukan intervensi tekanan darah diastole menjadi $81.03 \mathrm{mmHg}$. Dari hasil tersebut dapat diambil keseimpulan terdapat pengaruh yang antara intervensi hipnoterapi terhadap penurunan tekanan darah sistole kurang lebih $30 \mathrm{mmHg}$ dan untuk tekanan darah diastole sebanyak 10 $\mathrm{mmHg}$.

\section{DAFTAR PUSTAKA}

1. Brunner \& Suddarth. Buku Ajar Keperawatan Medikal Bedah. Jakarta : EGC ; 2013.

2. Kementrian Kesehatan Indonesia. Profil Kesehatan Indonesia Tahun 2015,
Jakarta : Kementrian Kesehatan Rl; 2015.

3. Kementrian Kesehatan Indonesia. Profil Kesehatan Indonesia Tahun 2016, Jakarta : Kementrian Kesehatan Rl; 2016.

4. Dinas Kesehatan Kota Tasikmalaya. Angka Penderita Hipertensi Tahun 2018, Tasikmalaya ; 2018

5. Kahija, YF. Hipnoterapi : Prinsip-Prinsip Dasar Praktik Psikoterapi. Gramedia Pustaka Utama. Jakarta ; 2009.

6. Closkey, JC, \& Bulecheck, G.M. Nursing Intervension Classification, Edisi ke 4. Mosby Tear Book, Inc. New York ; 2009

7. Sutrisno, Rahmawati, dan Haryanto. Pengaruh Hipnoterapi Terhadap Penurunan Tekanan Darah Pada Penderita Hipertensi Di Wilayah Kerja Puskesmas Penawangan II Kabupaten Grobogan. Jurnal Keperawatan Stikes Annur Purwodadi ; 2016

8. Nurddin, Irfan. Perawatan Lansia. Jakarta Timur ; 2019

9. Laksana. Modul Panduan Pelatihan Basic Hypnosis \& Hypnobirthing. Jakarta ; 2016

10. Irma dan Vera. Penerapan Hipnoterapi Terhadap Tekanan Darah Pada Lansia Penderita Hipertensi. Jurnal Profesi Keperawatan Akademi Keperawatan Krida Husada Kudus, 2019

11. Rifki, Arif dan Leo Yosdimyati. Pengaruh Hipnoterapi Terhadap Penurunan Tekanan Darah Penderita Hipertensi Di Jombatan Wilayah Kerja Puskesmas Jabon. Jombang : Jurnal Keperawatan Stikes Insan Cendekia Medika ; 2018

12. Nurprasetyo, Adi. Hipnoterapi Untuk Menurunkan Tekanan Darah Penderita Hipertensi Di Dusun Gamping Lor Ambarketawang Gamping Sleman Yogyakarta. Jurnal Keperawatan Unisa Yogyakarta ; 2016

13. Kuswandi, dkk. Modul Panduan Pelatihan Basic Hypnosis \& Hypnobirthing. Jakarta ; 2016

14. Kementrian Kesehatan Indonesia. Profil Kesehatan Indonesia Tahun 2014, Jakarta : Kementrian Kesehatan RI ; 2014. 
15. Suprapto, Ira Haryani. Menu Ampuh Atasi Hipertensi. Yogyakarta ; 2014.

16. Efendi, Ferry \& Makhfud. Keperawatan Kesehatan Komunitas Teori dan Praktik dalam Keperawatan. Jakarta : Salemba Medika ; 2009

17. Kementrian Kesehatan Indonesia. Profil Kesehatan Indonesia Tahun 2013, Jakarta : Kementrian Kesehatan RI ; 2013.

18. Notoatmodjo, Soekidjo. Metodologi Penelitian Kesehatan. Jakarta: Rineka Cipta 2014.

19. Hidayat, A. Aziz Alimul. Metode Penelitian Kebidanan Dan Teknik Analisis Data. Jakarta; 2014

20. Nursalam. Metode Penelitian IImu Keperawatan. Jakarta: Salemba Medika 2016.

21. Masturoh, Imas. Bahan Ajar Metodologi Penelitian Kesehatan, 2018.

22. Wulandari Ayu. Pengaruh Hipnoterapi Terhadap Penurunan Frekuensi Merokok Pada Remaja. Program pascasarjana Fakultas Psikologi Universitas Negeri Makasar, 2016.

23. Eko, Krisna dan Yetti. Penurunan Tekanan Darah Pada Klien Hipertensi Primer melalui Terapi Hipnosis. 2011 